\title{
Da percepção do mal como privação do bem à percepção do mal como
} oportunidade de redenção

From the Perception of Evil as Deprivation of Good to the Perception of Evil as an Opportunity for Redemption

\section{Renato Somberg Pfeffer*}

Fundação João Pinheiro de Minas Gerais (FJP) | Belo Horizonte, Brasil renatopfeffer@yahoo.com.br

Resumo: Este artigo busca discutir, de forma sucinta, como alguns filósofos judeus refletiram sobre o enigma do mal. Permeado de conflitos e contradições, o pensamento judaico sobre o tema tem sido discutido sob as vertentes ética e metafísica, porém, sempre partindo do pressuposto monoteísta característico do judaísmo. No primeiro apartado, o artigo analisa como Maimônides (1135-1204) afirma a ideia do mal como privação do bem. A segunda parte busca refletir sobre a promessa divina de salvação a partir de algumas ideias de Abraão Isaac Kook (18651935) e Joseph Dov Soloveichic (1903-1993). A título de reflexões finais, o artigo defende que a resposta do judaísmo à falta de sentido de uma vida de sofrimentos oculta um plano divino de construção de uma nova realidade apontando para a possibilidade da redenção.

Palavras-chave: Pensamento judaico. Mal. Redenção.

Abstract: This article seeks to discuss, in a succinct way, how some Jewish philosophers have reflected on the enigma of evil. Permeated with conflicts and contradictions, Jewish thinking about evil has been discussed under the ethical and metaphysical aspects, however, always starting from the monotheistic assumption characteristic of Judaism. In the first section, the article analyzes how Maimonides (1135-1204) affirms the idea of evil as a deprivation of good. The second section of the text seeks to reflect on the divine promise of salvation based on some ideas of Abraham Isaac Kook (1865-1935) and Joseph Dov Soloveichic (1903-1993). As a final reflection, the article argues that Judaism's response to the meaninglessness of a life of suffering hides a divine plan for building a new reality pointing to the possibility of redemption.

Keywords: Jewish Thought. Evil. Redemption.

* Doutor em Filosofia Tecnologia e Sociedade pela Universidad Complutense de Madri e Professor da Fundação João Pinheiro de Minas Gerais. 


\section{Introdução}

Mal metafísico designa em termos filosóficos o enigma do mal no mundo. A razão especulativa e as diferentes teodiceias religiosas, no entanto, foram incapazes de explicar o mistério do mal, o que deixa explícito os limites da razão humana. Juan Antonio Estrada afirma que somente quando a humanidade permite uma abertura da imanência à transcendência é possível encontrar um sentido na aparente irracionalidade que permeia as vivências humanas. ${ }^{1}$

Na busca de uma resposta para esse enigma, o religioso, em especial na tradição bíblica, encontra uma resposta no abandono esperançado e incondicional em Deus. $\mathrm{O}$ crente invoca Deus em vez de pensá-Lo racionalmente. Por outro lado, o Deus da Bíblia não é irracional, o que seria inconcebível para o ser humano. A crença em Deus deve ser, no mínimo, razoável para se enfrentar o enigma do mal. ${ }^{2}$

O mal metafísico é uma necessidade do mundo criado. Um mundo marcado pela imperfeição, contingência, relatividade e insuficiência. Tomás de Aquino (1225-1274) já afirmava que o mal é inerente à condição finita do ente. ${ }^{3}$ Ainda que Deus não deseje, o mal é parte da condição de criatura marcada por sua cota de imperfeição. Não tem sentido, portanto, a pergunta se Deus poderia ter criado um mundo mais harmônico e sem dor, pois a raiz última da possibilidade do mal reside na condição finita da realidade. Por outro lado, o excesso de mal no mundo impacta todos aqueles que se dedicam ao tema. Afinal, por que sofrem os inocentes? ${ }^{4}$

Andrés Torres Queiroga defende que o mal nos coloca frente ao absurdo da existência e tem levado a humanidade a buscar respostas, sejam laicas ou religiosas. ${ }^{5}$ Sem ter a pretensão de fazer uma análise profunda da vasta produção bibliográfica sobre o assunto, e partindo do princípio que a razão humana é insuficiente para decifrar o enigma do mal, o presente ensaio busca discutir, de forma sucinta, como alguns filósofos judeus refletiram sobre o enigma do mal. Na verdade, o artigo é composto por reflexões ainda incipientes de um projeto mais amplo de investigação da questão do enigma do mal na tradição bíblica hebraica, portanto, possui um alcance analítico limitado.

\footnotetext{
${ }^{1}$ ESTRADA, 1962.

2 FERNÁNDEZ DEL RIESGO, 2002.

${ }^{3}$ AQUINO, 1968.

${ }^{4}$ Sacks (2007) aventa a hipótese de que esse questionamento teria nascido junto com o monoteísmo. Culturas politeístas ou seculares, por não terem uma força única a governar o universo, não teriam esse tipo de dúvida.

5 TORRES QUEIROGA, 2011.
} 
A filosofia judaica propôs reflexões variadas acerca do enigma do mal por meio de diversos expoentes do mundo religioso e filosófico. Salom Rosemberg afirma que o filósofo judeu é alguém que aceita a autoridade das Sagradas Escrituras e demais fontes judaicas originais, mas ao mesmo tempo, busca conciliá-la com a autoridade da razão humana. ${ }^{6}$ Permeado de conflitos e contradições, o pensamento judaico sobre o mal e o bem tem sido discutido sob as vertentes ética e metafísica, porém, sempre partindo do pressuposto monoteísta característico do judaísmo.

No primeiro apartado, o artigo analisa como Maimônides (1135-1204) se opôs ao dualismo ético e metafísico que teve sua origem entre os persas e gregos. O filósofo judeu sustentará a ideia do mal como privação do bem. A visão cósmica do mal de Maimônides, no entanto, não dá uma resposta ao problema no nível pessoal. A salvação limitada proposta por ele, sem abalos naturais na ordem da natureza, não deixa claro como a promessa divina de acabar com o mal ocorrerá. $O$ segundo apartado do texto busca refletir sobre a promessa divina de salvação a partir de algumas ideias de Abraão Isaac Kook (1865-1935) e Joseph Dov Soloveichic (19031993). A título de reflexões finais, afirma-se que a resposta do judaísmo à falta de sentido de uma vida de sofrimentos oculta um plano divino de construção de uma nova realidade apontando para a possibilidade do ser humano alcançar a redenção.

\section{Maimônides e o mal como privação do bem}

Há uma explícita negação do dualismo persa e grego na tradição judaica: não existe um Deus na terra e outro no céu como afirmavam os persas, pois é o mesmo Deus que "forma a luz e cria a escuridão, (que) faz a paz e cria o mal". ${ }^{7}$ Da mesma forma, é contestado o dualismo grego que opunha matéria e forma. Ao longo da Idade Média, essa discussão que envolvia o dualismo derivou o debate sobre a origem da criação: teria ela surgido a partir de algo ou do nada, sendo que o primeiro pressuposto permitia pensar em uma causalidade divina. O dualismo ético e metafísico do gnosticismo, por exemplo, buscou mesclar concepções platônicas, crenças persas e concepções bíblicas. Os gnósticos afirmavam a existência de duas deidades, uma boa e outra má, mas não iguais como no pensamento persa. ${ }^{8}$

O platonismo, por sua vez, falava de uma ideia das ideias (Deus) e de um demiurgos que modulou o mundo material como uma cópia imperfeita dos arquétipos ideias. Essa contraposição entre divindades acabou convertendo "ao demiurgo um ser totalmente dependente de Deus e submetido a ele". ${ }^{9}$ Essas ideias macrocósmicas

\footnotetext{
${ }^{6}$ ROSEMBERG, 1996.

${ }^{7}$ Is $45: 7$

${ }^{8}$ FERNÁNDES DEL RIESGO, 2016, p. 272.

9 "Al demiurgo en un ser totalmente dependiente de Dios y sometido a Él" (ROSEMBERG, 1996, p. 25).
} 


\section{Arquivo Maaravi}

afetaram o microcosmo do homem, pois esse era considerado uma réplica do universo. Os gnósticos sustentarão que, assim como o universo, o homem é composto por duas partes, o corpo, material e imperfeito, e a alma, pertencente ao mundo ideal e que está sujeita ao cárcere do corpo. Nessa perspectiva, o mundo material é visto negativamente e a alma deve buscar sua libertação.

O judaísmo teve que lutar contra esse dualismo ético e metafísico do gnosticismo, em especial, com a concepção que falava de "Satã ou o mal como potência independente" ${ }^{10}$ Mesmo levando em conta que na Cabala (misticismo judaico) e no folclore judeu haja, por vezes, uma aceitação dessa teoria, predominou a tese de que tanto o bem quanto o mal provém da mesma fonte.

No seu livro Guia dos Perplexos, ${ }^{11}$ concluído por volta do ano de 1191, Maimônides sustentará, em oposição ao dualismo gnóstico, a ideia de mal como privação de algo. Deus, o criador de tudo, ao criar o bem possibilitou também sua privação, o mal. Ele aplica essa teoria aos âmbitos cósmico (morte, enfermidade, velhice, catástrofes naturais), social (guerras, bandidos) e pessoal (o mal que causamos a nós mesmos). ${ }^{12}$

A doutrina de Maimônides sobre o mal é enriquecida com sua hermenêutica sobre Satã no livro de Jó. No início dele, Satã comparece perante Deus em duas ocasiões com características distintas:

E num dia em que os filhos de Deus vieram apresentar-se perante o Senhor, veio também Satanás entre eles. Então o Senhor disse a Satanás: Donde vens? E Satanás respondeu ao Senhor, e disse: De rodear a terra, e passear por ela. ${ }^{13}$

E, vindo outro dia, em que os filhos de Deus vieram apresentar-se perante o Senhor, veio também Satanás entre eles, apresentar-se perante o Senhor. ${ }^{14}$

Em Jó 1:6-7, Satã se introduz às escondidas entre os filhos de Deus. Ele não é uma das potências por meio das quais Deus comanda o mundo; ele simplesmente aparece com a criação e seu poder se restringe à Terra. Satã representa a privação no mundo material que atormenta o homem juntamente com mal cósmico e social. No capítulo seguinte, ${ }^{15}$ no entanto, se apresenta como uma potência a mais frente ao Senhor. Este, segundo Jó, que Maimônides associa à figura talmúdica de Sammael, representa o mal

10 "Satã o el mal como potencia independiente" (FERNÁNDES DEL RIESGO, 2016, p. 272).

${ }^{11}$ MAIMÔNIDES, 1998.

${ }^{12}$ ROSEMBERG, 1996.

${ }^{13}$ Jó 1:6-7

14 Jó 2:1

${ }^{15}$ Jó 2:1 


\section{Arquivo Maaravi}

antropológico. Utilizando uma história talmúdica segundo a qual o ser humano é acompanhado de dois anjos, o que fica à esquerda representando o bem e o que fica à esquerda representando o mal, Maimônides associa o nome de Sammael à palavra Smol, que significa esquerda no hebraico. No homem há, portanto, duas potências, uma boa e outra má.

Rosemberg afirma que Maimônides identifica Satã com a imaginação que leva o homem a fazer o mal. ${ }^{16} \mathrm{O}$ lado bom, por sua vez, é associado à razão. Em princípio, a imaginação poderia ser concebida como uma força boa parte integrante do ser humano, mas seu perigo reside na possibilidade de que ela predomine sobre a racionalidade. A imaginação assim representaria o perigo da falta de hierarquia e autogoverno, uma privação de ordem que levaria a desejos, necessidades e crenças errôneas. Esse domínio da irracionalidade seria a origem do mal que os homens fazem uns aos outros homens. Somente com a vitória da racionalidade sobre a irracionalidade, o homem poderia se libertar.

A análise encetada por Maimônides acerca do relato do Jardim do Éden sobre a árvore do bem e do mal contido em Gênesis auxilia a compreensão de sua tese. ${ }^{17} \mathrm{De}$ forma geral, há duas intepretações básicas e contraditórias sobre o episódio. ${ }^{18} \mathrm{~A}$ primeira encara o relato como um mito pagão. ${ }^{19}$ Nessa perspectiva, Deus possui uma árvore extraordinária e, devido ao seu zelo ou inveja, não quer que o homem tenha acesso a ela. Outra interpretação, ainda nessa perspectiva de mito pagão, destaca a bondade de Deus, e não sua inveja: Ele não quer que o homem alcance o conhecimento porque esse é fonte de sofrimento. $\mathrm{O}$ conhecimento, assim, levaria a humanidade à consciência da mortalidade e da infinitude de angústias que marca sua vida. Há ainda a interpretação de índole sexual que vincula a árvore ao fato de Adão ter conhecido Eva. ${ }^{20}$

Em oposição a essa perspectiva pagã do relato genesíaco se coloca Maimônides e a maioria dos filósofos judeus. Essa segunda forma de pensar o mito se baseia na ideia de que a imagem de Deus no homem é representada pela racionalidade: "o homem é humano apenas porque tem conhecimento e sabedoria, só por causa da razão". ${ }^{21}$ Portanto, é absurdo pensar que o conhecimento possa ser fruto de um pecado.

\footnotetext{
${ }^{16}$ ROSEMBERG, 1996.

17 MAIMÔNIDES, 1998.

18 ROSEMBERG, 1996.

${ }^{19} \mathrm{BLOCH}, 1983$.

${ }^{20}$ FERNÁNDES DEL REISGO, 2016.

21 "Es hombre es humano tan solo porque tiene concimiento y sabidorya, solo a causa da razón" (ROSEMBERG, 1996, p. 74).
} 


\section{Arquivo Maaravi}

Ao refletir sobre o tema, Maimônidesafirma que a árvore da qual a bíblia trata não é a que distingue o conhecimento verdadeiro do falso. ${ }^{22}$ Ela é a árvore do conhecimento do bem e do mal a qual o homem tem acesso por meio do pecado. Adão teria sido levado ao pecado que gerou sua expulsão do Éden pelos apetites da imaginação. Ao pensar que Deus lhe escondia algo, Adão é atormentado por uma inquietude na busca de alcançar a clarividência. Ele assume a possibilidade do mal, e a consciência da distinção entre mal e bem, para poder assemelhar-se ao próprio Deus, mesmo com nefastas consequências. ${ }^{23}$

Na medida em que a serpente simboliza a vontade humana, ${ }^{24}$ é a imaginação que influencia Adão a cometer o despropósito de querer se igualar a Deus. ${ }^{25}$ Deus, ironicamente, segundo Maimônides, ${ }^{26}$ reage a ousadia do homem: "Agora o homem se tornou como um de nós, conhecendo o bem e o mal. Não se deve, pois, permitir que ele também tome do fruto da árvore da vida e o coma, e viva para sempre". ${ }^{27} \mathrm{Na}$ verdade, a imaginação engana o próprio homem prometendo algo que não pode cumprir. Maimônides nos coloca frente ao drama da condição humana que opõe imaginação e faculdades racionais. A primeira nos levando ao fracasso; a segunda que permite que acessemos as verdades reveladas na Torá. É no acesso racional ao conhecimento da Torá, também chamada de "árvore da vida", ${ }^{28}$ que se encontra o destino final e secreto do homem que consiste "em ultrapassar os limites do mundo espiritual e transcendente". ${ }^{29}$

Frente à teoria de uma vida regida pelo azar/acidente do epicurismo e do fatalismo/pessimismo de certas variantes do Islamismo e mesmo judaísmo, Maimônides sustenta uma teoria da liberdade da razão humana, que tem suas raízes na providência divina. ${ }^{30}$ Para ele, essas teorias partiam de um erro de perspectiva ao considerarem o homem como centro de tudo o que existe e julgar tudo do ponto de

\footnotetext{
${ }^{22}$ MAIMÔNIDES, 1998.

${ }^{23}$ JANKÉLEVITCH, 2011.

${ }^{24}$ ABRAVANEL citado por FERNÁNDES DEL REISGO, 2016, p. 275.

${ }^{25}$ O sábio talmúdico Eliezer (PIRKEI DE RABI ELIEZER 13), ao interpretar Ecl 10:11, afirma que a cobra que seduziu Adão e Eva era o Anjo Sammael que cavalgava numa espécie de camelo.

${ }^{26}$ MAIMÔNIDES, 1998.

${ }^{27} \mathrm{Gn} 3: 22$.

${ }^{28} \operatorname{Pr} 3: 18$.

29 "En aceder más allá de sus limites al mundo espiritual y transcendente" (ROSEMBERG, 1996, p. 76).

${ }^{30}$ MAIMÔNIDES, 1998.
} 


\section{Arquivo Maaravi}

vista egoísta do ser humano. Essa visão antropocêntrica desconsidera que nem toda realidade foi criada para servir ao homem. ${ }^{31}$

A visão cósmica de Maimônides, porém, tem o inconveniente de não resolver o problema em nível pessoal ${ }^{32}$. Frente aos pessimistas, ele defenderá que o que Deus quer com a criação, que foi um favor divino, é o bem cósmico na existência de todos os seres. Essa tese encontrou ampla aceitação nos filósofos judeus dos séculos 14 e $15 . .^{33}$

De qualquer forma, o dilema persiste: se o mundo não é alheio ao mal e ao sofrimento, como interpretar a promessa de Isaías que Deus "acabará com o mal definitivamente" ?34 Como conciliar o mal metafísico com a promessa divina? A reflexão sobre a providência divina envereda nesse ponto para o tema da salvação. Seria essa salvação cósmica, social, histórica e pessoal simultaneamente? Para Maimônides essa salvação seria limitada. ${ }^{35}$ Segundo ele, a ordem da natureza não sofrerá abalos radicais com o advento conflituoso da redenção, inclusive a morte continuará a existir. ${ }^{36}$ Crendo nessa salvação histórica no final dos tempos, que inclui a ideia de sobrevivência da alma em uma vida futura, ele acredita que essa será acompanhada pelo surgimento de uma sociedade perfeita. Assim, o homem desenvolverá plenamente suas capacidades e a criação alcançará sua finalidade.

\section{Indo além da percepção do mal como privação do bem: a possibilidade da redenção}

A questão do mal e da futura redenção suscitou - e ainda suscita - polêmicas acirradas no meio judaico. Para o israelita primitivo, por exemplo, a questão do mal não era explicada a partir da sobrevivência do indivíduo após a morte. O Sheol

${ }^{31}$ Maimônides (1998) recorda que antes de criar o homem no livro de Gênesis, Deus havia criado várias coisas que também eram boas.

${ }^{32}$ Esse é um dos motivos da persistência da persistência de doutrinas pessimistas no campo da espiritualidade (mística do Budismo, Schopenhauer, entre outras) que sustentam o retorno do ser ao não ser como único caminho do bem triunfar sobre o mal (ROSEMBERG, 1996).

${ }^{33}$ ROSEMBERG, 1996.

${ }^{34}$ Is $25: 8$

${ }^{35}$ MAIMÔNIDES, 1998.

${ }^{36}$ Em Iggeret Teiman (carta à comunidade o Iêmen), no entanto, Maimônides não descarta a possibilidade de que a redenção obedeça a uma ordem miraculosa e ocorra sem conflitos, ao contrário do que ocorreria em uma evolução natural. (Disponível

em: https://www.sefaria.org/Iggerot_HaRambam\%2C_Iggeret_Teiman?lang=bi. Acesso em: 10 set. 2019. 


\section{Arquivo Maaravi}

Revista Digital de Estudos Judaicos da UFMG

ISSN: 1982-3053

bíblico era apenas um lugar tenebroso onde se misturavam bons e maus. Nada indicava uma conotação de retribuição no além, pois qualquer forma de justiça deveria ocorrer neste mundo. Isso acabava deixando a deriva o antigo israelita quando ele se confrontava com as experiências concretas da vida, em especial a vitória do malvado sobre o justo. ${ }^{37}$ Restava ao israelita primitivo o abandono gratuito e esperançado em Deus. Ao longo do tempo, a busca de salvação frente à questão do sofrimento acabou orientando os hebreus para uma ideia de vida e retribuição ultraterrenas que não eram explícitas na tradição bíblica original. Nesse processo, a crença messiânica acaba abraçando a concepção de ressurreição dos mortos que expressa a ânsia por justiça universal ao vencer o mal histórico e reconciliando a humanidade consigo mesma. Tal preocupação é uma presença constante na filosofia e teologia judaicas, como se tentou demonstrar no apartado anterior por meio do otimismo limitado de Maimônides.

Abraão Isaac Kook (1865-1935), em sintonia com o multifacetado universo da Cabala e do Hassidismo, se oporá a ao otimismo moderado de Maimônides. Ao contrário do filósofo medieval que concebia o mal como privação do bem, Kook considerava o mal com algo real e estruturado que existiria em simetria com o bem. ${ }^{38}$ Nesse mesmo sentido, um dos ramos mais relevantes do hassidismo, o movimento Chabad fundado por Rabi Shneur Zalman de Liadi (1745-1812), afirma que o descenso de Deus aos planos inferiores, ocorrido por meio de condensações de diversos tipos e do ocultamento do semblante divino (Tzimtzumnim), ${ }^{39}$ acabou provocando a criação das coisas impuras (kelipót) e do lado sombrio (sitra achra). Essas kelipót também são chamadas de outros deuses (elohim acherim), porque, apesar de se nutrirem e terem sua vitalidade originadas no plano da santidade, não derivam do verdadeiro desejo

37 Isso fica explícito na história de Jó. Quando ele acusa Deus, não recebe uma resposta. Na verdade, Deus afirma o descabimento de suas intenções de dialogar com Ele de igual para igual. O livro não é apocalíptico e escatológico: não se encontra ali uma saída compensatória no Juízo Final ou a ideia de redenção final do homem e do mundo, típico dos discursos proféticos. Por outro lado, a história de Jó possui as características típicas da tradição bíblica de queda e elevação que irá influenciar, em um momento histórico posterior, as esperanças messiânicas e apocalípticas (FERNÁNDEZ DEL RIESGO, 2016).

${ }^{38}$ KOOK, 2006.

${ }^{39}$ De forma simplificada, o conceito de Tzimtzum é uma noção cabalista que se refere ao primeiro ato criativo de Deus, que contraiu sua luz infinita, gerando um espaço vazio, para que as todas as coisas pudessem existir. Essa ocultação foi tão poderosa que, do ponto de vista espiritual, a escuridão passou a reinar no mundo físico onde são encontradas as kelipot (conchas ou cascas que simbolizam as forças do mal ou o desperdício espiritual) e os poderes profanos contrários a Deus (sitra achra, o "outro lado"). 
de Deus (do Seu semblante), e sim da parte traseira da santidade (achoraím). Mesmo sendo uma abominação para Deus, Shneur Zalman defende que a sitra achra possui uma quantidade mínima de luz e vida que é absorvida do aspecto externo da santidade divina que está em estado de exílio dentro dela. ${ }^{40}$

Para Kook, o mal é um desejo de destruição que está em todas as criaturas. Se aproximando do dualismo da Cabala, ele acreditava que o homem, enquanto uma reprodução em miniatura da realidade cósmica, possui em seu ser uma tendência para o bem e para o mal. Ao ativar o mal ou o bem dentro de si mesmo, o homem ativava o mal ou o bem cósmico, respectivamente. O paradoxo dessa visão dualista é que ela permite uma vitória definitiva sobre o mal, inclusive o mal cósmico, pois é possível transformar a natureza. A percepção do mal como privação em Maimônides, ao contrário, não permitia que o homem, com seus esforços, pudesse aperfeiçoar o mundo a ponto de derrotar a morte.

Utilizando uma imagem idealista da Cabala, Kook descreve a realidade como uma árvore invertida com as raízes escondidas no céu. $O$ tronco e os galhos são a realidade como a percebemos permeada pelo mau, as raízes, por outro lado, são boas. Dessa forma, o que vemos é uma ilusão e não a realidade em si mesma. "Na luta em que mantemos, estamos no meio de um sonho que despertamos, como defende o pensamento hassídico" ${ }^{41} \mathrm{O}$ despertar desse sonho ocorrerá pelo progresso histórico onde o bem avançará sobre o mal e o mundo será aperfeiçoado: "a salvação consiste no progresso ascendente da vitória do bem sobre o mal". ${ }^{42}$

Joseph Dov Soloveichic, importante pensador existencialista judeu da atualidade ${ }^{43}$, discute essa questão do mal em seu ensaio Kol Dodi Dofek. ${ }^{44}$ Partindo do episódio bíblico onde Moisés pede a Deus para ver sua glória e conhecer seus caminhos, ${ }^{45} \mathrm{O}$ autor afirma que esse pedido é o mesmo que está presente em Jó e em outros livros do Antigo Testamento que tomam consciência do enigma do mal. Ele salienta a responsabilidade do indivíduo que se confronta durante a vida com eventos caóticos e cataclísmicos que o obriga a lidar com o mal admitindo sua existência. $\mathrm{O}$ homem, então,

rastreia os fundamentos intelectuais do sofrimento e do mal, e procura encontrar a harmonia e equilíbrio entre a afirmação e a negação e para neutralizar a ponta afiada da tese - o bom - e o

\footnotetext{
40 ZALMAN, 2019.

${ }^{41}$ FERNÁNDES DEL RIESGO, 2016, p. 277.

${ }^{42}$ ROSEMBERG, 1996, p. 111.

${ }^{43}$ ROSEMBERG, 1996.

${ }^{44}$ SOLOVEICHIC, 1992.

${ }^{45}$ Ex 33:13.
} 


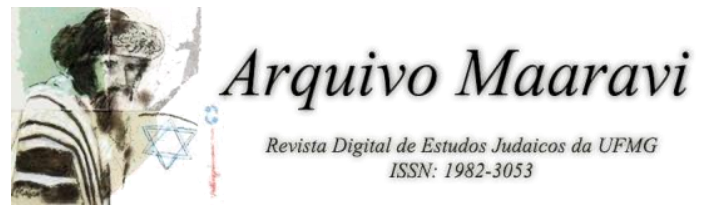

contrário - o mal na existência [...] até o ponto de auto-ilusão - a negação da existência do mal no mundo. ${ }^{46}$

Frente ao enigma do mal, Joseph Dov Soloveichic aponta para a existência de duas explicações: a sorte ou a missão. A primeira trata o homem como um objeto imerso na sua existência, porém, com a capacidade de se fazer perguntas sobre o bem e o mal. A resposta que esse homem encontra é o silencio de Deus retratado no livro de Jó. Esse tipo de pensamento especulativo associava o mal à privação do bem e não havia dado uma resposta satisfatória para captar a essência dos atos divinos, por isso, era necessário buscar outra resposta. A segunda explicação parte do princípio de que o homem, apesar detentor do livre arbítrio, é sujeito de sua história e possui uma missão. Nascido como objeto, o homem é capaz se tornar sujeito e transformar sua sorte em missão. Nesse caso, a resposta ao enigma do mal deixa de ser especulativa e o sofrimento derivado do mal passa a ser encarado como uma oportunidade para "a purificação do homem e a santificação do seu espírito" ${ }^{47}$

Soloveichicainda acrescenta, lembrando que Jó só foi redimido após começar a rezar por seus companheiros, que a única resposta possível frente ao sofrimento é atender o sofrimento alheio. ${ }^{48}$ Enquanto Jó era um objeto passivo que questionava Deus, ele só encontrou o silêncio. Ao se tornar um sujeito e rezar e se preocupar pelo sofrimento de seus companheiros, ele encontrou a redenção.

\section{Reflexões finais}

Sacks afirma que os místicos judeus distinguiram entre dois tipos de encontro divino-humano: it'aruta de-l'eyla e it'aruta de-l'tata. ${ }^{49} \mathrm{O}$ primeiro é um despertar do alto iniciado por Deus, o segundo um despertar de baixo promovido pelo homem..$^{50}$ O despertar do alto é espetacular e sobrenatural rompendo as cadeias de causalidade que marcam a natureza. $\mathrm{O}$ despertar de baixo é gesto humano e que não altera $\mathrm{o}$ mundo natural. Por outro lado, o despertar do alto, apesar de ser avassalador, é efêmero e não muda a natureza humana. $O$ despertar de baixo, por sua vez, deixa uma marca permanente no ser humano expandindo seus horizontes e transformando o mundo interior. ${ }^{51}$ "As batalhas lutadas por nós não nos mudam; as batalhas que

\footnotetext{
${ }^{46}$ SOLOVEICHIC, 1992, p. 53.

${ }^{47}$ ROSEMBERG, 1996, p. 124).

${ }^{48}$ SOLOVICHIC, 1992.

${ }^{49}$ SACKS, 2018.
}

${ }^{50}$ A revelação do Sinai é um exemplo do despertar iniciado do alto, a construção do tabernáculo no deserto pelos hebreus, por sua vez, exemplifica o despertar de baixo. ${ }^{51}$ A efemeridade do despertar do alto e sua influência passageira sobre o homem podem ser ilustradas pelo pecado do bezerro de ouro que ocorreu apenas quarenta 
lutamos, nos mudam"52. Sacks exemplifica esse encontro do homem com Deus por meio das duas tábuas da lei que Moisés recebeu no monte Sinai. As primeiras tábuas recebidas eram somente Torá she-bichtav, a Torá escrita sem interferência humana. As segundas tábuas, recebidas por Moisés foram a Torá she-b'al peh, a Torá Oral, que era uma parceria na qual o homem interpretava a palavra de Deus. Isso explica porque foi somente após as segundas tábuas que a face de Moisés se tornou radiante. ${ }^{53}$

A recepção das primeiras tábuas foi passiva e não alterou a essência de Moisés. Sacks conclui que no judaísmo o natural é maior que o sobrenatural, pois é no despertar de baixo, onde tomamos a iniciativa de nos aproximar de Deus, que provoca uma transformação duradoura em nós e no mundo. Por isso, Jó só obteve a redenção quando passou a lutar contra o sofrimento dos outros. Esse é um aspecto essencial do pensamento judaico: a recusa em abordar a realidade e buscar uma reconciliação universal deixando de lado ou esquecendo as diferenças. Tal característica faz com que os perdedores e inocentes da história passem a ter voz, desafiando a abstração da razão dos vencedores. ${ }^{54} \mathrm{O}$ julgamento da história no pensamento judaico se vincula à memória histórica se alimentado da solidariedade dos derrotados. Mantendo vivas as recordações do que havia sido esquecido, ocorre uma reconciliação retrotativa, "um olhar para a frente e outro para trás". ${ }^{55}$ Isso é fundamental, pois uma reconciliação verdadeira não pode ser abstrata.

Os direitos pendentes do passado que geraram sofrimento são como um passado que não passa e afeta o presente. Os direitos das vítimas não têm prazo de prescrição mesmo que os vencedores da história queiram esquecê-los. $\mathrm{O}$ antídoto para o possível esquecimento é o papel da memória, qual seja: ver o mundo pelos olhos das vítimas. ${ }^{56}$ Sem esse olhar do oprimido sobre a experiência histórica do mal, a compreensão da verdade sobre a realidade presente permaneceria oculta.

Dessa análise, constata-se que os direitos e dignidade dos sujeitos particulares são inegociáveis se almejamos uma sociedade fundada na verdadeira ética e na justiça universal. Esse ideal que exige que vivos e mortos tenham seus direitos reconhecidos nos coloca frente à teologia judaica, em especial, frente ao conceito cabalístico de Tikun, termo que expressa a ideia de redenção como volta das coisas ao seu estado original e o anúncio de um novo futuro ${ }^{57}$. A memória por si só, portanto, não é capaz

dias após a revelação do Sinai. Após a construção do santuário, por sua vez, os israelitas não fizeram mais ídolos durante a travessia do deserto.

52 SACKS, 2018.

${ }^{53}$ Ex 34:29.

${ }^{54}$ MATE, 1991.

${ }^{55}$ FERNÁNDES DEL RIESGO, 2016, p. 357).

${ }^{56}$ MARDONES; MATE, 2003.

${ }^{57}$ MATE em MARDONES; MATE, 2003. 
de salvar; ela necessita da ideia de ressurreição. Ou como diria Adorno, ${ }^{58}$ apesar de sua dialética que resistia à crença religiosa, "o passado não tem outra esperança que a de, abandonado ao infortúnio, ressurgir transformado" por meio de uma ruptura futura da história.

O teólogo Jean Bautista Metz chama essa sensibilidade do pensamento judaico em relação à memória das vítimas de história de razão anamnética. ${ }^{59}$ Razão essa que está vinculada uma maneira única de ver o presente e com o componente redentor do messianismo. Essa utopia messiânica é diferente das utopias modernas abstratas e transcendentais, pois é uma resposta no presente para as dúvidas humanas baseada na interrupção da evolução histórica. Essa possibilidade de uma descontinuidade temporal gerada pela redenção messiânica situa o crente além da história alimentando a esperança de uma justiça universal que repare o sofrimento humano. Sendo sustentada pela esperança religiosa, essa ideia só pode ser evocada metafórica e simbolicamente afastando-se, assim, da racionalidade reduzida da argumentação e da crítica.$^{60}$ Em suma, ao partir dos sonhos frustrados e direitos pendentes daqueles que sofreram no passado, o pensamento messiânico judaico legitima moralmente um futuro de justiça.

Na complexa tradição do pensamento judaico, discutida de forma incompleta nesse texto, o mal como privação do bem é uma possibilidade inerente à criação. Em oposição ao dualismo gnóstico, o monoteísmo judaico reafirma que o mesmo Deus que criou o bem criou o mal, pois o positivo implica no negativo. $O$ mal seria, portanto, uma potência presente na natureza humana e no cosmos e é identificado no irracionalismo, na desordem, na necessidade. Como o mistério do mal é inacessível ao homem, o pensamento judeu recomenda o abandono no mistério acolhedor de Deus que é animado pela esperança de uma libertação que dê sentido e repare a realidade. Mesmo sendo esse sentido da realidade algo oculto do homem, ele deve continuar confiando em Deus, pois o encontro com Ele não é com o absurdo, e sim com o mistério. Em oposição ao pessimismo niilista, o judaísmo constatava que essa falta de sentido de uma vida marcada pelo sofrimento ocultava algo divino que poderia dar origem à construção de uma nova realidade. Indo além da percepção do mal como privação do bem, a tradição filosófica judaica aponta para a possibilidade do ser humano alcançar a redenção, se tornando sujeito de sua história que é

58 ADORNO, 1987, p. 96. É interessante como essa passagem em Adorno abre a possibilidade de um futuro renovado que é de difícil conjugação com o seu pessimismo e com sua dialética que resistem a uma reconciliação final, no entanto, tal temática escapa ao escopo do presente artigo.

${ }^{59}$ METZ; WEISEL, 1996.

${ }^{60}$ MARDONES; MATE, 2003. 


\section{Arquivo Maaravi}

Revista Digital de Estudos Judaicos da UFMG

ISSN: 1982-3053

transformada em missão de resgate dos direitos pendentes do passado que geraram sofrimento.

\section{Referências}

ADORNO, Theodor. W. Minima Moralia. Madrid: Taurus, 1987.

AQUINO, Tomás de. Summa contra gentilis. v. 2. Madrid: BAC, 1968.

BÍBLIA on-line. Disponível em: https:// https://www.bibliaonline.com.br. Acesso em: 5 abr. 2018.

BLOCH, E. El ateísmo en el cristianismo. Madrid: Taurus, 1983.

ESTRADA, J. A. Razones y sin razones de la creencia religiosa. Madrid: Tecnos, 1962.

FERNÁNDES DEL RIESGO, Manuel. Ética y religión: La insuficiencia de la experiencia moral. Madrid: Escolar y Mayo Editores, 2016.

FERNÁNDES DEL RIESGO, Manuel. El enigma de la condición humana: un diálogo entre la razón y la fe. La ciudad de Dios: Real Monasterio del Escorial, 2002.

IGGERET TEIMAN. Disponível em: https://www.sefaria.org/Iggerot_HaRambam\%2C_Iggeret_Teiman?lang=bi. Acesso em: 10 set. 2019.

JANKÉLEVITCH, V. Lo puro y lo impuro. Buenos Aires: Las cuarenta, 2011.

KOOK, Abraão Isaac. The Essential Writings of Abraham Isaac Kook. New Jersey: Ben Yehuda Press, 2006.

MAIMÔNIDES. Guía de Perplejos. Madrid: Trotta, 1998.

MATE, R. En torno a una justicia anamnética. In: MARDONES, J. M.; MATE, R. (Org.). La ética ante las víctimas. Barcelona: Antrophos, 2003. p. 100-125.

MATE, R. La razón de los vencidos. Barcelona: Antrophos, 1991.

MARDONES, J. M.; MATE, R. (Org.). La ética ante las víctimas. Barcelona: Antrophos, 2003.

METZ, J. B.; WEISEL, E. Esperar apesar de todo. Madrid: Trotta, 1996.

ROSEMBERG, Salom. El bien y el mal. Madrid. Ediciones de la Universidad Autónoma de Madrid, 1996.

SACKS, Jonathan. Duas vezes, duas tábuas. Disponível em: https:/pt.chabad.org/library/article_cdo/aid/2483039/jewish/Duas-Vezes-DuasTbuas.htm. Acesso em: 20 fev. 2018.

SACKS, Jonathan. Para cura um mundo fraturado. São Paulo: Ed. Sêfer, 2007. 


\section{Arquivo Maaravi}

Revista Digital de Estudos Judaicos da UFMG

SOLOVEICHIC, Joseph Dov. Kol Dodi Dofek: It Is the Voice of My Beloved That Knocketh. In: ROSEMBERG, B. (Org.). Theological and halakhic reflections on holocaust. H. New Jersey: Ktav Publishing House, 1992. p. 51-188.

TORÁ VIVA. Trad. Adolfo Wasserman com anotações do Rabino Aryeh Kaplan. São Paulo: Editora Maayanot, 2000.

TORRES QUEIROGA, A. Repensar el mal. De la ponerología a la teodicea. Madrid: Trotta: 2011.

ZALMAN, Shneur. Likutei Amarim. Capítulo 22. Jabad.com, 23 jan. 2019. Disponível em: https://es.chabad.org/dailystudy/tanya.asp?tDate=1/23/2019. Acesso em: 25 jan. 2019.

Recebido em: 13/09/2020.

Aprovado em: 23/09/2020. 